DOI 10.37882/2223-2982.2021.07.07

\title{
СПЕЦИФИКА ПОДГОТОВКИ ИНСТРУКТОРА НОВОГО ПОКОЛЕНИЯ ДЛЯ ОБУЧЕНИЯ ПЕРСОНАЛА АТОМНЫХ СТАНЦИЙ, СТРОЯЩИХСЯ ЗА РУБЕЖОМ ПО РОССИЙСКИМ ПРОЕКТАМ
}

\section{THE SPECIFICS OF TRAINING A NEW GENERATION OF INSTRUCTORS FOR TRAINING PERSONNEL OF NUCLEAR POWER PLANTS UNDER CONSTRUCTION ABROAD ON RUSSIAN PROJECTS}

M. Gordeev

G. Khoroshavina

Summary: The article deals with the issues of the industry order for the training of a new generation of instructors for the training of AES personnel in the conditions of the implementation of an international investment project. The authors propose a rationale for the feasibility and timeliness of solving this problem by the logic of digital transformation and the manifestation of the properties of convergent education. The article systematizes the factors of innovative orientation and conditionality of psychological and pedagogical training of instructors of the new generation. It is also emphasized that the core of innovation is formed by the methodology of pedagogical science.

Keywords: professional training, industry order, digital transformation, international standard of professional training, pedagogical orientation of the project.
$\Gamma$ осударственные приоритеты развития экономики на период до 2030 г. определяют достижение конкурентоспособности инновационной экономики России на тренде шестой длинной волны качеством подготовки отраслевых кадров. Предприятиями отрасли атомной энергетики совершенствование профессиональной подготовки кадров в фокусе реалий цифровой технологической революции разворачивается на основе обновления подходов к педагогическим технологиям профессионального обучения.

Перед отраслевой корпоративной подготовкой квалифицированных специалистов логикой технологического развития цифровой трансформации выдвинута актуальная педагогическая задача: создание условий для достижения высокой производительности обучения разработкой инвестиционных образовательных проектов по подготовке корпоративного корпуса преподавателей и специалистов профессионального обучения. В
Гордеев Максим Александрович Аспирант, ФГБОУ ДПО «ИРДПО», г. Москва

Хорошавина Галина Долматовна

Д.п.н., профессор, МГТУ им. Н.Э. Баумана, г. Москва galinaxor@mail.ru

Аннотация: В статье рассматриваются вопросы отраслевого заказа подготовки инструктора нового поколения для обучения персонала АЭСв условиях реализации международного инвестиционного проекта. Авторы предлагают обоснование целесообразности и своевременности решения данной задачи логикой цифровой трансформации и проявлением свойств конвергентного образования. В статье систематизированы факторы инновационной направленности и обусловленности психолого-педагогической подготовки инструкторов нового поколения. Также подчеркивается, что ядро инноваций формируется методологией педагогической науки.

Ключевые слова: профессиональная подготовка, отраслевой заказ, цифровая трансформация, международный стандарт профессиональной подготовки, педагогическая направленность проекта.

том числе, совершенствованием практики подготовки инструкторов по подготовке персонала АЭС вновь строящихся за рубежом ядерных объектов.

Выбор приоритета был обоснован масштабными проектами формирования зарубежного пула заказов отрасли. В стратегии атомной энергетики строительство за рубежом - главный тренд ближайших пяти лет. Проект Госкорпорации «Росатом» «Международное сотрудничество в сфере ядерного образования» нацелен на содействие созданию и развитию национальной системы ядерного образования стран-партнеров с использованием российских образовательных технологий.

Комплекс образовательных вопросов международного инвестиционного проекта, которым актуализируется исследование научных подходов к реализации специальных образовательных программ подготовки инструктора нового поколения для обучения персонала 
АЭС, включает:

- Обучение иностранных отраслевых специалистов;

- создание современной образовательной инфраструктуры для подготовки кадров странпартнеров;

- популяризация российского ядерного образования;

- продвижение российских ядерных технологий за рубежом;

- обеспечение разработки и контроля исполнения планов обучения персонала АЭС в странах-новичках.

АНО ДПО «Техническая академия Росатома» в рамках международного инвестиционного проекта «Подготовка и дополнительное профессиональное образование персонала ядерной инфраструктуры, персонала подрядных организаций, эксплуатационного персонала атомных станций, строящихся за рубежом по российским проектам» выступает центром консолидации предложений российских организаций, работающих в области ядерного образования, с целью содействия в развитии национальной системы ядерного образования в странах-партнёрах и поддержки сотрудничества российских и зарубежных вузов в интересах национальных ядерных программ[1].

В рамках международного инвестиционного проекта формируется интеллектуальное сотрудничество между представителями университетов стран-партнёров и России. На основе взаимодействия с российскими профильными университетами действует Ассоциация «Консорциума опорных вузов Госкорпорации «Росатом» (МИФИ, МГУ, МЭИ, НГТУ, СПбПУ, ТПУ, УрФУ и др.) и зарубежных организаций высшего и специального образования в республике Беларусь, в государствах Востока, Вьетнаме, Египте, в странах Евросоюза, ЮАР, и Японии.

Для подготовки нового поколения инструкторов ведется разработка новых англоязычных учебников по ядерным технологиям. Реализация международного проекта сопряжена с подготовкой преподавательского состава университетов стран-партнёров, которая осуществляется в формате «Train-The-Trainers»: между университетами стран-партнёров и РФ в поддержке национальных ядерных проектов оказывается помощь в разработке совместных образовательных программ по ядерным технологиям.

Закономерный характер выдвижения педагогической задачи методологией педагогической науки объясняется сменой образовательной парадигмы на этапе перехода к постиндустриальному обществу, что означает отказ от понимания образования, как получение готового знания, и понимание образования, как достояния личности, как средства ее самореализации, как средство построения карьеры. Новые условия инновационного развития предприятий отрасли, цифровая трансформация производства и международный контекст развития отрасли, определили ядро инноваций в профессиональной подготовке инструкторов, готовности к непрерывному профессиональному росту и обновлению не только инженерно-технологических компетенций, но и компетенций социально-организационного и интеллектуального профиля.

В основе инноваций в разработке содержания, форм и методов обучения инструктора нового поколения по подготовке персонала АЭС лежат закономерности педагогической науки. Исследователи и практики педагогической науки подчеркивают, что вопросы организации профессионального обучения «должны решать только педагогически грамотные и подготовленные к решению этих задач работники» [2].

Реализация корпоративного международного инвестиционного проекта «Подготовка и дополнительное профессиональное образование персонала ядерной инфраструктуры, персонала подрядных организаций, эксплуатационного персонала атомных станций, строящихся за рубежом по российским проектам» на площадке «Технической Академии Росатома» позволила обосновать и систематизировать совокупность факторов, которые раскрывают инновационную направленность и обусловленность психолого-педагогической подготовки инструкторов в корпорации:

1. тенденции развития Индустрии 4.0 промышленной революции и цифровой трансформации отрасли;

2. «педагогико-технологические» основания конвергентного образования, конвергентные педагогические технологии [3], закономерности «встречной трансформации» образовательного процесса и цифровых технологий и средств [4], научные исследования отечественных педагогов по проблемам цифровизации отечественного образования;

3. потенциал технологических ресурсов цифровой инфраструктуры профессионального обучения;

4. возможности международной мобильности ресурсов корпорации в организационной инфраструктуре профессиональной подготовки;

5. ценностно-смысловые (аксиологические) аспекты в профессиональной подготовке, развитие ментальных и социально значимых личностных качеств педагога-инструктора нового поколения;

6. стимулирование познавательной активности участников профессионального обучения;

Новая роль инструктора нового поколения для подготовки персонала строящихся за рубежом атомных станций обозначена эвристическим характером проек- 
тирования образовательных программ профессиональной подготовки на основе междисциплинарного взаимодействия и освоения технологических инноваций. Деятельность инструктора усложняется и дает импульс учебной активности обучающихся. Мотивация и профессионализм будущего инструктора, его методический потенциал, создают основание высокой производительности учебного процесса. Интенсивность учебной деятельности нарастает, так как компьютеры «обеспечивают возможность решать большое количество разнообразных технологических задач за малые промежутки времени, что определяет быстродействие, универсальность и, как следствие, их востребованность» [5].Технологические возможности web-интерфейса увеличивают разнообразие форм учебно-методического материала, обеспечивают наличие обратной связи, предоставляют информацию баз данных, динамических фрагментов вебинаров, материалов социальных сетей. На дидактические свойства цифровых технологий указывает В.И. Блинов и его коллеги, отмечая их интерактивность, мультимедийность, гипертекстовость, персональность, субкультурность.

Преимущества корпоративного обучения, которые проявляются в целостности и непрерывности подготовки нового поколения кадров профессионального обучения, формируется интеграцией корпоративных ресурсов производства и образования, возможностя- ми диверсификации программ обучения, повышения квалификации и переподготовки кадров, исходя из запросов отрасли, создают благоприятные условия для реализации международного проекта подготовки инструктора нового поколения. С одной стороны, в распоряжении будущих инструкторов технические инновации производства, с другой стороны, готовность работников к развитию способностей, к достижению профессионализма и мастерства.

Принимая во внимание, что отношения между наукой, технологией, инженерией и математикой становятся все более прочными, для педагога профессионального образования становятся актуальными прикладные аспекты инженерной педагогики, кросс-культурного управления, управления знаниями, билингвальной подготовки. Такая практика реализуется в научно-образовательном пространстве «Технической Академии Росатома», на основе синтеза знаний, умений, навыков и накопления опыта в реализации международного образовательного проекта подготовки инструктора нового поколения[6].

Для наукоемкого производства атомной энергетики периода цифровой трансформации и интеллектуализации труда и производства акцент на педагогическом ядре в преобразовании профессиональной подготовки инструкторов для эксплуатационных подразделений госкорпорации стал одним из важных направлений обновления корпоративных образовательных ресурсов.

\section{ЛИТЕРАТУРА}

1. Дух взаимодействия. Дайджест Технической Академии Росатома. Обнинск: ТАР, 2019.

2. Методология профессионального образования// Сборник материалов международной научно-практической конференции, посвященной А.М. Новикову/ Под науч. ред. Т.Ю. Ломакиной. 1 декабря 2016 г./ФГБНУ ИСРО РАО. - М.: ФГБНУ «Институт стратегии развития образования РАО, 2016. - 648 с. - С.90

3. Роберт И.В. Научно-педагогические практики как результат конвергенции педагогической науки и информационных и коммуникативных технологий// Педагогическая информатика. 2017.№3. - С.27 - 41

4. Блинов В.И., Сергеев И.С., Есенина Е.Ю. Основные идеи дидактической концепции цифрового профессионального образования и обучения. М.: Издательство «Перо», 2019. - С.7

5. Роберт И.В. Развитие информатизации образования на основе цифровых технологий: интеллектуализация процесса обучения, возможные негативные последствия: https://https:D0110.17238/issn1998-5320.2017.30.65

6. Гордеев М.А. К вопросу о проектировании компетенций педагогов дополнительного профессионального образования нового поколения//Ученые записки университета имени П.Ф Лесгафта. - 2020. - №12 (162)

(с) Гордеев Максим Александрович, Хорошавина Галина Долматовна (galinaxor@mail.ru). Журнал «Современная наука: актуальные проблемы теории и практики» 